DOI: $10.1111 /$ cea.13884

Asthma and Rhinitis

\title{
Heterogeneity of the pharmacologic treatment of allergic rhinitis in Europe based on MIDAS and OTCims platforms
}

\author{
Jean Bousquet ${ }^{1,2,3,4}$ @ | Detlef Schröder-Bernhardi ${ }^{5}$ | Claus Bachert ${ }^{6,7,8,9}$ | \\ G. Walter Canonica ${ }^{10}$ | Victoria Cardona ${ }^{11}$ ( ) | Elisio M. Costa ${ }^{12}$ | \\ Wienczyslawa Czarlewski $^{13}$ | Philippe Devillier ${ }^{14}$ ( Joao A. Fonseca ${ }^{15,16}$ | \\ Ludger Klimek $^{17,18,19}$ | Piotr Kuna ${ }^{20}$ | Olga Lourenco ${ }^{21}$ | Joaquim Mullol ${ }^{22,23}$ \\ Oliver Pfaar ${ }^{24} \odot$ | Nhân Pham-Thi ${ }^{25}$ | Boleslaw Samolinski ${ }^{26}$ | Julia Saueressig ${ }^{5}$ | \\ Glenis K. Scadding ${ }^{27}$ | Ann-Kathrin Stroh ${ }^{5}$ | Sophie Scheire ${ }^{28}$ | Eric Van Ganse ${ }^{29,30}$ — \\ Torsten Zuberbier ${ }^{1,2}$
}

${ }^{1}$ Charité Universitätsmedizin Berlin, Humboldt-Universität zu Berlin, Berlin, Germany

${ }^{2}$ Department of Dermatology and Allergy, Comprehensive Allergy Center, Berlin Institute of Health, Berlin, Germany

${ }^{3}$ University Hospital Montpellier, Montpellier, France

${ }^{4}$ MACVIA-France, Montpellier, France

${ }^{5}$ IQVIA Consumer Health, Frankfurt, Germany

${ }^{6}$ Upper Airways Research Laboratory, ENT Dept, Ghent University Hospital, Ghent, Belgium

${ }^{7}$ International Airway Research Center, First Affiliated Hospital Guangzou, Sun Yat-sen University, Guangzou, China

${ }^{8}$ Division of ENT Diseases, CLINTEC, Karolinska Institutet, Stockholm, Sweden

${ }^{9}$ Department of ENT Diseases, Karolinska University Hospital, Stockholm, Sweden

${ }^{10}$ Personalized Medicine Asthma, \& Allergy Clinic-Humanitas University \& Research Hospital, IRCCS-Milano, Milano, Italy

${ }^{11}$ Allergy Section, Department of Internal Medicine, Hospital Vall d'Hebron \& ARADyAL Research Network, Barcelona, Spain

${ }^{12} \mathrm{UCIBIO}$, REQUINTE, Faculty of Pharmacy and Competence Center on Active and Healthy Ageing of University of Porto (Porto4Ageing), Porto, Portugal

${ }^{13}$ Medical Consulting Czarlewski, Levallois, France

${ }^{14}$ Unité de Recherche en Pharmacologie Respiratoire, Pôle des Maladies des Voies Respiratoires, Hôpital Foch, Université Paris-Saclay, Suresnes, France

${ }^{15}$ CINTESIS, Center for Research in Health Technology and Information Systems, Faculdade de Medicina da Universidade do Porto, Lda Porto, Portugal

${ }^{16}$ Medida, Lda Porto, Portugal

${ }^{17}$ Center Department of Otolaryngology, Head and Neck Surgery, Universitätsmedizin Mainz, Mainz, Germany

${ }^{18}$ Center for Rhinology and Allergology, Wiesbaden, Germany

${ }^{19}$ Department of Otolaryngology, Head and Neck Surgery, Universitätsmedizin Mainz, Mainz, Germany

${ }^{20}$ Division of Internal Medicine, Asthma and Allergy, Barlicki University Hospital, Medical University of Lodz, Lodz, Poland

${ }^{21}$ Faculty of Health Sciences and CICS - UBI, Health Sciences Research Centre, University of Beira Interior, Covilhã, Portugal

${ }^{22}$ Rhinology Unit \& Smell Clinic, ENT Department, Hospital Clínic, Barcelona, Spain

${ }^{23}$ Clinical \& Experimental Respiratory Immunoallergy, IDIBAPS, CIBERES, University of Barcelona, Barcelona, Spain

${ }^{24}$ Section of Rhinology and Allergy, Department of Otorhinolaryngology, Head and Neck Surgery, University Hospital Marburg, Philipps-Universität Marburg, Marburg, Germany

${ }^{25}$ Ecole Polytechnique Palaiseau, IRBA (Institut de Recherche bio-Médicale des Armées), Bretigny, France

${ }^{26}$ Department of Prevention of Environmental Hazards, Allergology and Immunology, Medical University of Warsaw, Warsaw, Poland

${ }^{27}$ The Royal National ENT Hospital, University College London, London, UK

${ }^{28}$ Pharmaceutical Care Unit, Faculty of Pharmaceutical Sciences, Ghent University, Ghent, Belgium

${ }^{29}$ PELyon, Lyon, France

${ }^{30}$ HESPER 7425, Health Services and Performance Research, Université Claude Bernard Lyon, Lyon, France

This is an open access article under the terms of the Creative Commons Attribution-NonCommercial License, which permits use, distribution and reproduction in any medium, provided the original work is properly cited and is not used for commercial purposes.

The Authors. Clinical \& Experimental Allergy published by John Wiley \& Sons Ltd. 


\section{Correspondence}

Jean Bousquet, 273 avenue d'Occitanie,

Montpellier 34090, France.

Email: jean.bousquet@orange.fr

\section{Abstract}

Background: The practice of allergology varies widely between countries, and the costs and sales for the treatment of rhinitis differ depending on practices and health systems. To understand these differences and their implications, the rhinitis market was studied in some of the EU countries.

Methods: We conducted a pharmaco-epidemiological database analysis to assess the medications that were being prescribed for allergic rhinitis in the years 2016, 2017 and 2018. We used the IQVIA platforms for prescribed medicines (MIDAS ${ }^{\circledR}-$ Meaningful Integration of Data, Analytics and Services) and for OTC medicines (OTC International Market Tracking-OTCims). We selected the five most important markets in the EU (France, Germany, Italy, Poland and Spain).

Results: Intranasal decongestants were excluded from the analyses because they are rarely prescribed for allergic rhinitis. For both Standard Units (SU) and costs, France is leading the other countries. In terms of SU, the four other countries are similar. For costs, Poland is lower than the three others. However, medication use differs largely. For 2018, in SU, intranasal corticosteroid is the first treatment in Poland (70.0\%), France (51.3\%), Spain (51.1\%) and Germany (50.3\%), whereas the Italian market is dominated by systemic antihistamines (41.4\%) followed by intranasal corticosteroids (30.1\%). Results of other years were similar.

Discussion: There are major differences between countries in terms of rhinoconjunctivitis medication usage.

\section{KEYWORDS}

allergic rhinitis, costs, medications, MIDAS, units

\section{1 | INTRODUCTION}

Allergic rhinitis (AR) is one of the most common chronic conditions. Available treatments include allergen avoidance, pharmacotherapy with $\mathrm{H}_{1}$-antihistamines or intranasal corticosteroids (INCS) and allergen-specific immunotherapy (AIT). ${ }^{1}$ Many patients are dissatisfied with their treatment for various reasons. Management does not consider the patients' needs, no cure is available, adherence to long-term therapy is poor, and/or the patients do not fully understand their condition. Real-world data obtained via mobile technology have suggested that there are differences in medication use between countries. ${ }^{2,3}$

MASK-air ${ }^{4-6}$ is a Good Practice of DG Santé concerning the digital transformation of health., ${ }^{7,8}$ The practice of allergology varies widely between countries, and the costs and sales for the treatment of rhinitis differ depending on practices and health systems. To understand these differences and their implications, it is important to have an overall view of the rhinitis market in some of the EU countries.

The goal of this paper was to assess practices in different EU countries in order to better implement the Good Practice of DG Santé (MASK-air). The secondary goal was to understand some of the differences and to propose mitigation strategies. This study will serve as a baseline status for possible future measures to be taken at the country level.

\section{2 | METHODS}

\section{1 | Study design}

This ARIA study evaluated the market for allergic rhinitis (AR) treatment (prescribed and over-the-counter (OTC) medications) in five EU countries in the years 2016-18. We conducted a pharmacoepidemiological database analysis to assess the medications that were prescribed for allergic rhinitis during the years 2016, 2017 and 2018. We used the IQVIA (collaboration between Quintiles and IMS Health under the name 'IQVIA') platforms for prescribed medicines (MIDAS ${ }^{\circledR}$-Meaningful Integration of Data, Analytics and Services) ${ }^{9-11}$ and for OTC medicines (OTC International Market Tracking-OTCims). ${ }^{12}$ PharMetrics Plus database (IQVIA), a large health claims database, captures demographics, physician visits, hospitalizations and prescription drugs. All medical diagnoses are captured through the International Classification of Diseases, Ninth and Tenth Editions (ICD-9 and ICD-10). This database also captures all outpatient prescription drugs and includes drug identification, 
dose prescribed and treatment duration. We used manufacturing costs rather than costs for the healthcare system as, in some countries, there are rebates that are not publicly available.

\section{2 | Medications}

\subsubsection{Definitions used}

We used SU (Standard Units) and LEU/MNF (Local Currency Euro/ Manufacturer Price Level) to compare data between countries.

An SU is a unit defined by IQVIA to represent the smallest daily unit of consumption, for example one tablet, one vial/ampoule or $5 \mathrm{ml}$ of liquid. As an example, a pack of 100 tablets with a dosage recommendation of two tablets a day will lead to Unit $=1$, Counting Units $=100$ and $\mathrm{SU}=50$.

LEU/MNF per year represents the total sales in Local Currency Euro at Ex-Manufacturer Price Level per Calendar Year.

We chose Manufacturing Cost of the drugs, and it was not possible to mention healthcare system costs due to rebates that are not publicly available.

\subsection{2 | Selection of medications}

We selected medications registered for AR, as well as nasal or ocular decongestants which may also be administered for AR.

The World Health Organization (WHO) Anatomical Therapeutic Chemical (ATC) classifies drugs by their active ingredients ${ }^{13}$ and their defined daily dose (DDD), a fixed attribute that allows the conduct of national or international drug use studies. ${ }^{14}$ This ATC system is based on the earlier Anatomical Classification System, which was intended as a tool for the pharmaceutical industry to classify pharmaceutical products (as opposed to their active ingredients). ${ }^{15}$ This system was initiated in 1971 by the European Pharmaceutical Market Research Association (EphMRA). ${ }^{16,17}$ In the present study, we used the EphMRA system and gave the ATC correspondence.

For prescribed medications, the study was performed by IQVIA Ltd., London, England, using de-identified prescription data from MIDAS $^{\circledR}$ for 2016, 2017 and 2018 (in $€$ for sales) as well as numbers of treatments. MIDAS ${ }^{\circledR}$ provides connectivity and international standardization of national-level pharmaceutical audits to allow the cross-country analysis of company and product performance, as well as additional insights and attributes not available at a local level. MIDAS ${ }^{\circledR}$ captures and harmonizes the data from 92 countries worldwide, mainly for registered medicines (prescription and non-prescription) in pharmacy and hospital channels. MIDAS ${ }^{\circledR}$ integrates and extends IMS National Audits that accurately detail estimated product volumes, trends and market share by product and therapy class, through retail and non-retail channels. MIDAS ${ }^{\circledR}$ tracks the direct sales (i.e. sales invoices) of pharmaceuticals from the manufacturer to pharmacies or hospitals. MIDAS ${ }^{\circledR}$ also tracks indirect sales (sales going through a middleman, i.e. the wholesaler) to pharmacies and hospitals. MIDAS ${ }^{\circledR}$ tracks inflow or what these different channels are purchasing (i.e. the sales made into those outlets). It represents the full European market through representative panel projections for both retail and hospital channels.

The following subgroups include symptomatic AR drugs and ophthalmic drugs (since rhinitis is often associated with conjunctivitis). Montelukast was not used as it is an asthma and a rhinitis treatment and is only indicated in patients with both rhinitis and asthma. The following medications were considered (Table 1).

For OTC medications, the QuintilesIMS OTCims (OTC International Market Tracking) database was used. OTCims is a Customized Global Information Offering that provides granular data for the effective tracking of company and competitor performance in the Consumer Health marketplace. It uses IQVIA Consumer Health Classification based on Market Positioning. Data are available across four main market segments: OTC, Personal Care, Patient Care and Nutrition. Data are included for 36 countries from Europe, Asia Pacific, and North and Latin America. Clients are supported in both own as well as competitor product/pack performance tracking against key performance indicators.

The MIDAS $^{\circledR}$ database does not identify the disease for which the medication has been used. This is the case for systemic antihistamines (R06A0) which include treatments for the nose, skin and other organs. They cannot be distinguished. INCS (R01A1) can also be administered for AR, non-allergic rhinitis and rhinosinusitis.

The list of OTC medications is given in Table 2. The four OTC therapy classes include 'oral H1-antihistamines' and 'INCS'. The list is too far from ATC to propose any correspondence.

\section{3 | Allergen-specific immunotherapy}

The only country where AIT is mostly delivered in pharmacies is Germany. We only provided data for AIT in Germany (allergens, $\mathrm{V} 1 \mathrm{A0})$.

\subsection{1 | Selection of countries}

The market for prescribed medications (in costs for patients) for 2018 in all EU countries was ranked in order to choose the markets with the highest sales (Table S1). OTC medications were not considered in the country selection because a single database cannot be used in all countries. AIT was not considered in the country selection since large variations exist between countries in terms of supply (pharmacies, hospitals, Named-Patient Products, etc.).

The first six countries with the highest sales for AR medications and nasal decongestants were France, Germany, Italy, Spain, Poland and the UK. There was a big gap between UK $N^{\circ} 6$ and Sweden $N^{\circ} 7$. Thus, we considered only the first six countries. In the UK, a significant proportion of sales took place in supermarkets and these were not considered by IQVIA. Thus, the country had to be excluded. 
TABLE 1 Codes of prescribed medications

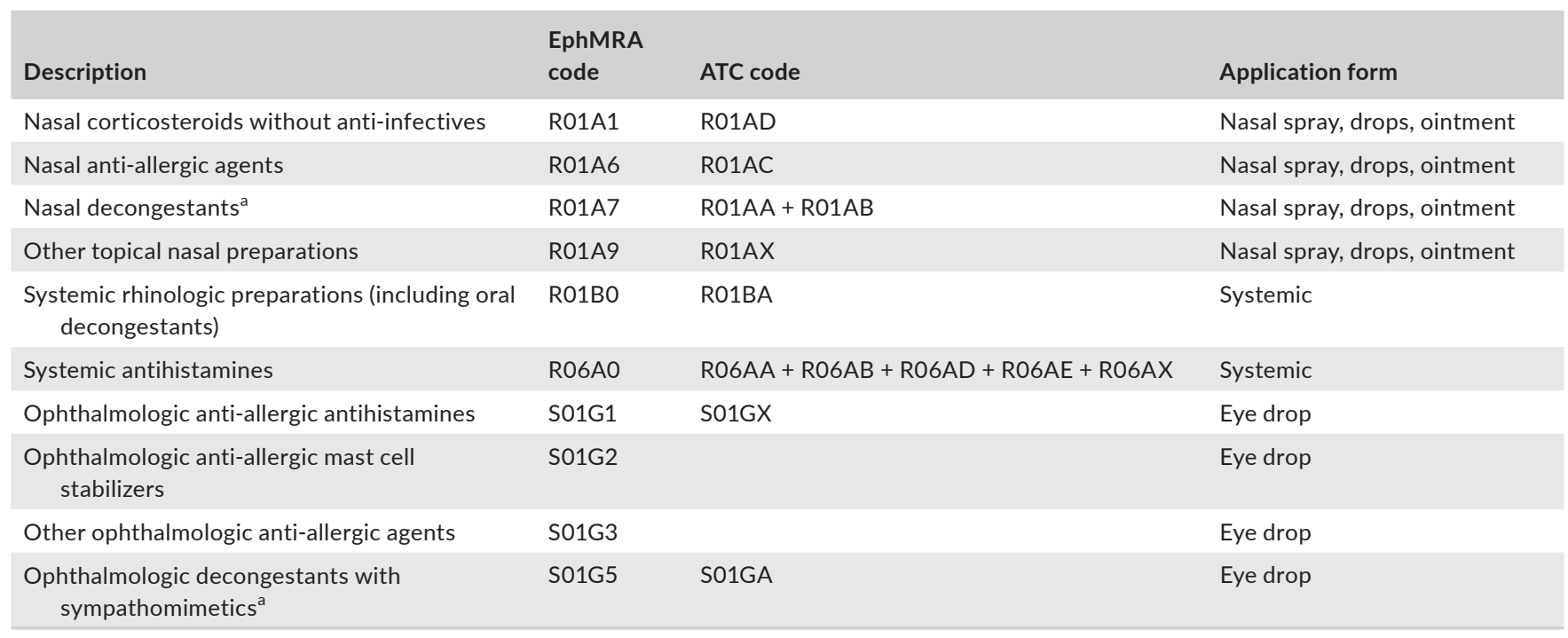

ancluded although not indicated in allergic rhinitis but may be used.

TABLE 2 Codes of over-the-counter (OTC) medications

\begin{tabular}{|ll}
\hline Description & $\begin{array}{l}\text { OTC } \\
\text { class }\end{array}$ \\
\hline Nasal decongestants & 01B2 \\
\hline Respiratory \& general antiallergics & $01 \mathrm{E} 1$ \\
\hline Eye antiallergics & $07 \mathrm{~A} 2$ \\
\hline Eye decongestants \& anti-inflammatories & $07 \mathrm{~A} 5$ \\
\hline
\end{tabular}

The 'Sell-Out' (Medication dispensed in pharmacies) data and, if not available, the 'Sell-In' (Medication delivered in pharmacies) data were obtained from IQVIA. For the countries selected, the databases were from different origins, and the data type differed taking into account the country specificities on drug dispensing (Table 3 ).

\subsection{Collection of information}

There are different methods of collecting the information, and we needed to make assumptions.

It is possible to compare 'Sell-in' (from wholesaler to retail pharmacy, effects like stocking are included) and 'Sell-out' (from retail pharmacy to patient) data, bearing in mind some biases. Therefore, for one quarter, the 'Sell-in' data might be higher when compared to 'Sell-out' due to stock, but these effects are minimized for yearly data. In the countries tested, 'hospital' means hospital consumption from hospital to patient.

For the OTCims Panel, all panels are 'Sell-out'.

\section{5 | Analyses}

We conducted a descriptive analysis to evaluate the medications used in different countries. To derive figures for anti-rhinitis consumption per person over the three years, we linked consumption by $\mathrm{SU}$ to population estimates.

Stratification: The analyses were performed separately for prescription data and OTC data. In some countries, the same products could be prescribed and were also available OTC. Thus, in order to prevent multiple counts, a complex merger process between prescriptions and OTC was necessary.

Data periods: The analyses covered the periods 2016, 2017 and 2018. Results were processed on a yearly basis.

Analyses were performed once at the same time.

Projection: The results were projected yearly per country.

\section{3 | RESULTS}

\section{1 | Intranasal decongestants (R1A7 and 01B2)}

Intranasal decongestant sales (R1A7 and 01B2) are extremely variable, with low sales in France (from 612,073 to 751,739 kSU per year, $12.6 \%-14.8 \%$ of total sales) and high sales in Germany (from $6,586,460$ to $6,890,822 \mathrm{kSU}$ per year, $71.6 \%-79.6 \%$ ) (Table 4). We checked the monthly variation of R1A7 in Germany in 2018 and found that they were purchased less often during the pollen season than outside (Figure S4). In Germany, although the majority of products were available in pharmacies, they were non-prescribed. We therefore excluded R1A7 and 01B2 from further analyses as they are unlikely to represent patients with allergic rhinitis.

\section{2 | Overall results without intranasal decongestants (R1A7 and 01B2)}

The results are presented in Table S2, Table 5 and Figure 1. For both $\mathrm{SU}$ and costs, France is leading the other countries. In terms of SU, 
TABLE 3 Origin of the databases

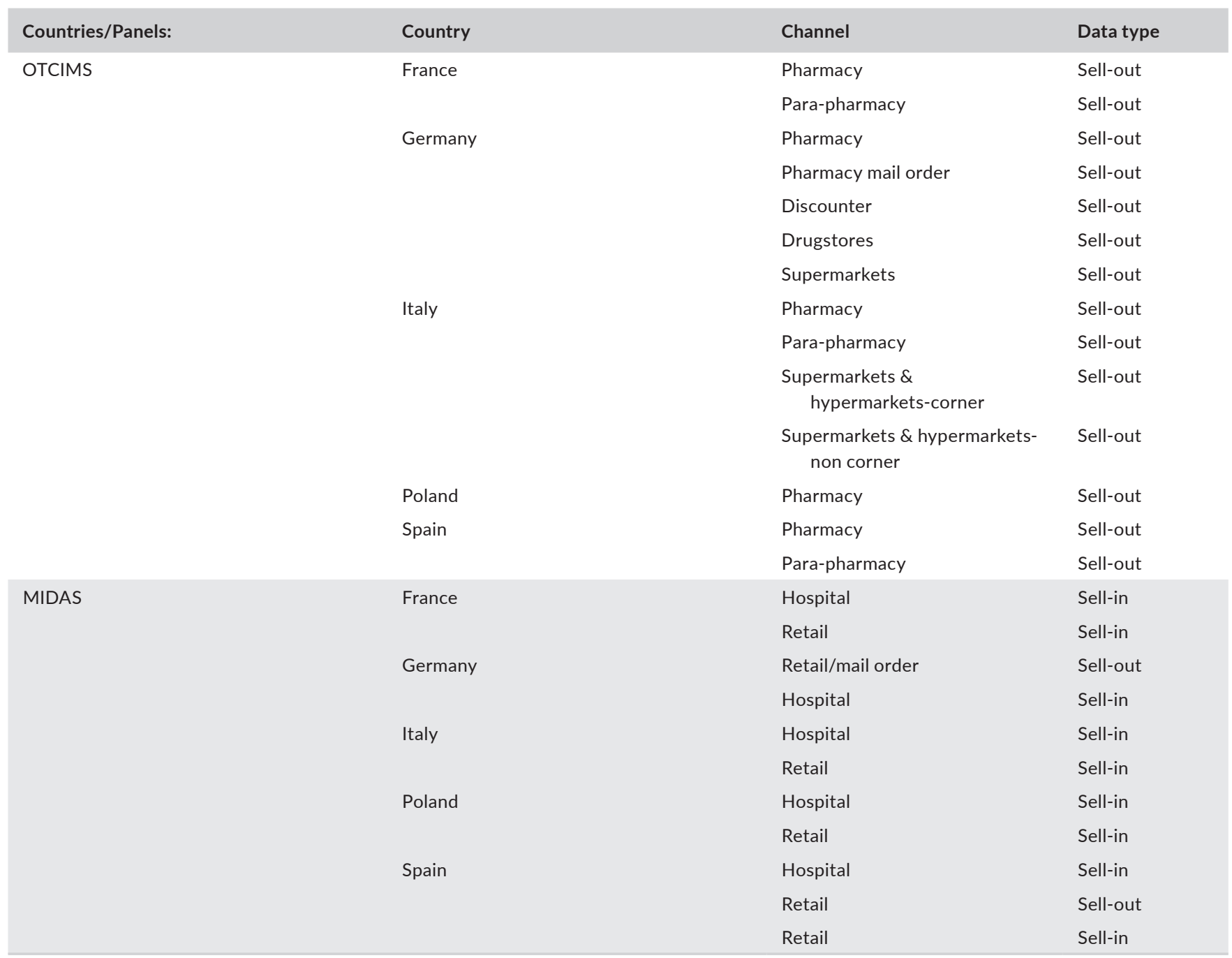

the four other countries are similar. For costs, Poland is lower than the three others. However, medication use differs largely. For 2018, in SU, INCS is the first treatment in Poland (70.0\%), France (51.3\%), Spain (51.1\%) and Germany (50.3\%), whereas the Italian market is dominated by systemic antihistamines $(41.4 \%)$ followed by INCS (30.1\%). Results of other years are similar. MPAze-Flu (DYMISTA) is represented from less than $1 \%$ in Spain to $1.5 \%$ in Poland and Germany and to around 2.6\% in France of SU in 2018.

In costs for 2018 , INCS represent $20.7 \%$ of the market in Poland, around $26-28 \%$ in Germany, Italy and Spain, and up to $38.6 \%$ in France. Systemic antihistamines represent from $45.8 \%$ (Italy) to $49.3 \%$ (France), $57 \%$ to $59 \%$ (Germany, Spain) and $67 \%$ (Poland).

\section{3 | Rhinoconjunctivitis medication consumption per person in Europe}

There are very large differences in medication consumption (SU) per person in Europe depending on the country (Table 6). In France, there are 4.3 times more INCS sold per inhabitant than in Germany. On the other hand, in Germany, there are 9.25 times more nasal decongestants sold per inhabitant than in France.

Although the proportion of reimbursement/out of pocket differs between countries, and even in the same country, for different classes of drugs, reimbursement and OTC availability of medications differ in EU countries (Table S3).

\subsection{Allergen immunotherapy}

In Germany, AIT represents between $33.2 \%$ and $37.3 \%$ of LEU/MNF (Table 4).

\section{4 | DISCUSSION}

The present paper shows that there is a great heterogeneity in AR medications across Europe. Some explanations may be proposed including reimbursement strategies. 
TABLE 4 Overall units and costs obtained by MIDAS and OTCims

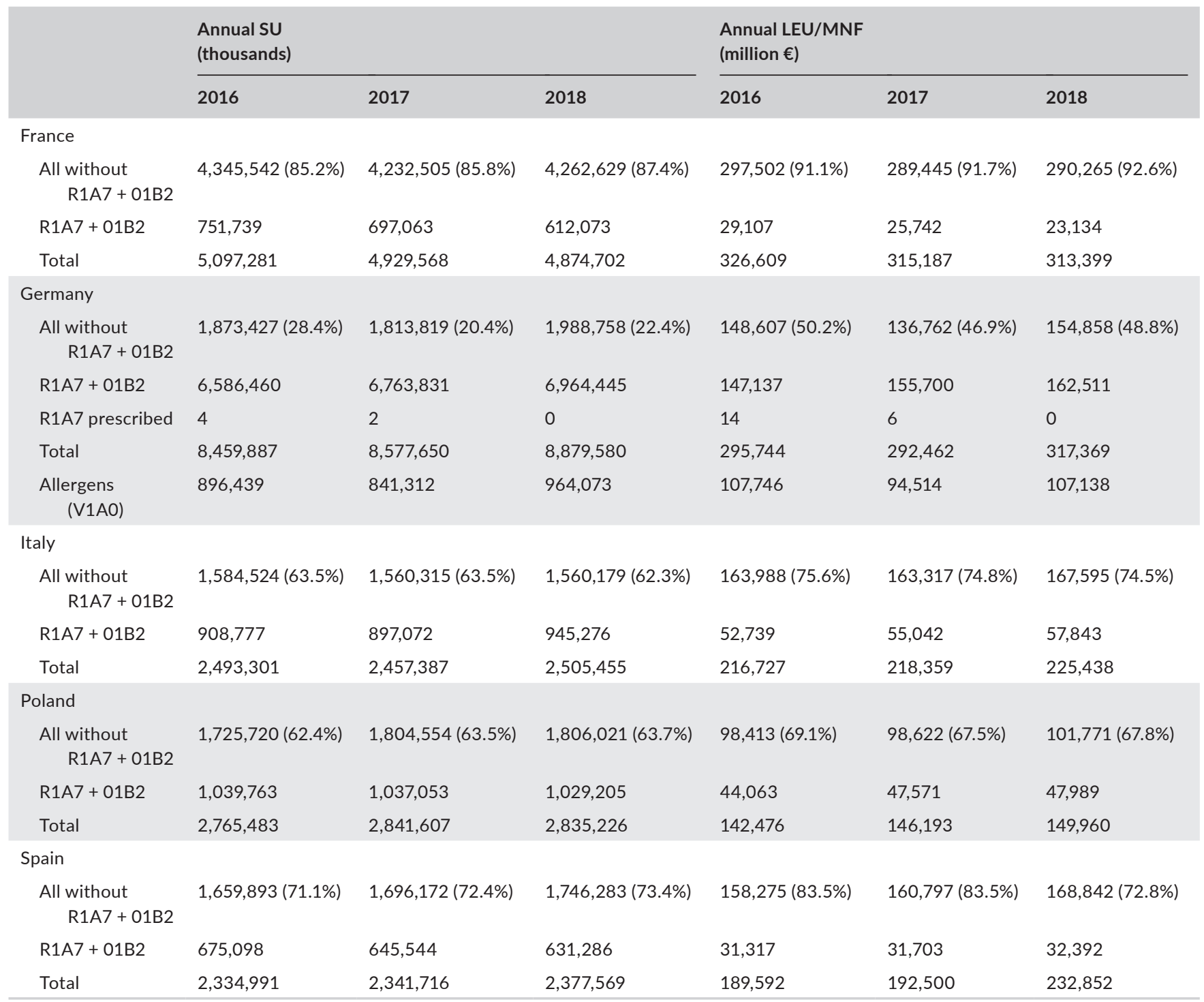

\section{1 | Limitations}

Although the IQVIA platform appears to be a good source of data for estimating drug consumption in different countries, there are several limitations.

First, we can only use the classification of medications proposed by IQVIA and some classes assess medications for multiple diseases such as 'Systemic antihistamines'. It is likely that their use differs between countries and that the results reported in this paper may not be totally comparable.

Second, in the IQVIA database, medications are not classified by disease and there are overlaps between skin and respiratory diseases. Furthermore, in respiratory diseases, there are different indications such as allergic and non-allergic rhinitis or rhinosinusitis.

Third, we had to make assumptions that were discussed in the methods. It does not seem that these estimations may have led to significant problems.
Fourth, another limitation is non-adherence to prescribed drugs in patients that cannot be estimated. Thus, the results of the study do not consider lack of adherence to medication which was reported to be quite high. ${ }^{18}$

Finally, the exclusion of nasal decongestants was proposed because they are not indicated in AR and are largely used for common cold and cough in some countries. The BSCAI guidelines (the only European guidelines) ${ }^{19}$ and ARIA (global guidelines) ${ }^{20}$ - used in most European countries - do not recommend the regular use of intranasal decongestants. In ARIA, the last recommendation was made in 2010; there have not been any other important papers on the subject since. In adults with AR and severe nasal obstruction, we suggest a very short course (no longer than 5 days, and preferably shorter) of intranasal decongestants while co-administering other drugs (conditional recommendation, very low-quality evidence). We suggest that clinicians should not administer and that parents should not use intranasal decongestants in preschool children 
TABLE 5 Standard units (SU) and costs of medications (LEU/MNF, absolute for fiscal year) in five European countries based on MIDAS and OTCims

\begin{tabular}{|c|c|c|c|c|c|c|}
\hline & $\begin{array}{l}\text { Standard units } \\
2016 \text { (Absolute) }\end{array}$ & $\begin{array}{l}\text { Standard units } \\
2017 \text { (Absolute) }\end{array}$ & $\begin{array}{l}\text { Standard units } \\
2018 \text { (Absolute) }\end{array}$ & $\begin{array}{l}\text { LEU/MNF } 2016 \\
\text { (Absolute) }\end{array}$ & $\begin{array}{l}\text { LEU/MNF } 2017 \\
\text { (Absolute) }\end{array}$ & $\begin{array}{l}\text { LEU/MNF } 2018 \\
\text { (Absolute) }\end{array}$ \\
\hline France & $5,097,280,885$ & $4,929,568,274$ & $4,874,702,206$ & $326,609,288$ & $315,187,283$ & $313,398,985$ \\
\hline R1A1 & $4,430,987$ & $3,142,635$ & $3,408,948$ & 323,730 & 307,361 & 336,467 \\
\hline R1A7 & $4,165,245$ & $3,735,215$ & $3,600,270$ & 61,833 & 52,174 & 48,840 \\
\hline *Dymista & 0 & 720 & 144,840 & 0 & 74 & 13,948 \\
\hline S1G1 & 14,980 & 13,119 & 20,349 & 1198 & 1095 & 1636 \\
\hline S1G2 & $3,376,938$ & $3,251,404$ & $4,251,647$ & 126,016 & 124,745 & 153,377 \\
\hline S1G3 & 63,456 & 35,431 & 170,362 & 2455 & 1587 & 7990 \\
\hline Retail & $4,690,535,231$ & $4,530,115,204$ & $4,493,777,976$ & $303,069,376$ & $292,933,322$ & $290,997,700$ \\
\hline${ }^{*}$ Dymista & 796,680 & $34,165,320$ & $114,622,080$ & 113,530 & $3,444,710$ & $11,462,208$ \\
\hline S1G1 & $50,009,780$ & $47,470,270$ & $48,741,660$ & $4,633,682$ & $4,569,464$ & $4,788,785$ \\
\hline S1G2 & $592,278,142$ & $570,187,400$ & $570,438,348$ & $20,262,676$ & $19,507,566$ & $19,794,182$ \\
\hline S1G3 & $124,342,080$ & $121,533,540$ & $118,854,280$ & $6,222,569$ & $6,249,301$ & $6,210,793$ \\
\hline Off-Take & $360,521,721$ & $352,837,569$ & $333,455,785$ & $19,074,984$ & $17,810,498$ & $17,700,707$ \\
\hline 01B2 & $343,489,664$ & $332,041,918$ & $297,306,639$ & $16,300,087$ & $14,656,459$ & $13,563,859$ \\
\hline O1E1 & $5,346,125$ & $7,039,683$ & $23,249,372$ & 821,915 & 938,080 & $1,998,837$ \\
\hline 07A2 & 400 & 0 & 0 & 13 & 0 & 0 \\
\hline Germany & $8,474,999,252$ & $8,595,106,633$ & $8,898,547,120$ & $691,220,202$ & $686,781,024$ & $707,408,598$ \\
\hline Hospital & $249,496,527$ & $255,184,305$ & $250,282,157$ & $8,711,628$ & $7,863,795$ & $8,272,906$ \\
\hline R1A1 & $5,474,147$ & $5,439,325$ & $5,575,688$ & 324,277 & 282,455 & 299,298 \\
\hline R1A7 & $228,397,070$ & $234,976,448$ & $229,199,632$ & $2,923,767$ & $2,942,361$ & $2,909,478$ \\
\hline R6A0 & $13,346,015$ & $12,761,105$ & $13,384,968$ & $2,066,290$ & $1,923,863$ & $2,484,365$ \\
\hline V1A0 & 17,442 & 12,954 & 13,269 & $3,335,043$ & $2,668,134$ & $2,524,879$ \\
\hline *Dymista & 64,240 & 44,400 & 72,120 & 10,675 & 7400 & 12,154 \\
\hline S1G1 & 291,274 & 303,232 & 410,628 & 10,349 & 11,407 & 11,025 \\
\hline S1G2 & $1,387,085$ & $1,278,129$ & $1,156,591$ & 16,949 & 13,627 & 14,754 \\
\hline S1G3 & 583,494 & 413,112 & 541,381 & 34,953 & 21,948 & 29,107 \\
\hline Phmscope & $7,867,016,585$ & $7,966,630,528$ & $8,257,235,986$ & $674,286,284$ & $669,888,195$ & $689,539,848$ \\
\hline R1A1 & $775,921,033$ & $755,819,069$ & $829,008,199$ & $37,308,422$ & $37,331,516$ & $42,471,934$ \\
\hline R1A7 & $6,231,082,998$ & $6,396,953,648$ & $6,486,356,795$ & $139,382,223$ & $148,708,228$ & $155,314,296$ \\
\hline R6A0 & $564,852,155$ & $543,717,940$ & $608,321,693$ & $92,324,525$ & $80,342,707$ & $88,917,806$ \\
\hline V1A0 & $15,095,779$ & $17,444,001$ & $18,953,549$ & $392,140,744$ & $391,651,448$ & $387,486,192$ \\
\hline${ }^{*}$ Dymista & $36,562,768$ & $34,240,092$ & $36,755,760$ & $6,093,972$ & $5,706,703$ & $6,165,471$ \\
\hline S1G1 & $39,119,160$ & $33,719,080$ & $44,437,320$ & $2,479,823$ & $2,128,481$ & $2,849,695$ \\
\hline
\end{tabular}


TABLE 5 (Continued)

\begin{tabular}{|c|c|c|c|c|c|c|}
\hline & $\begin{array}{l}\text { Standard units } \\
2016 \text { (Absolute) }\end{array}$ & $\begin{array}{l}\text { Standard units } \\
2017 \text { (Absolute) }\end{array}$ & $\begin{array}{l}\text { Standard units } \\
2018 \text { (Absolute) }\end{array}$ & $\begin{array}{l}\text { LEU/MNF } 2016 \\
\text { (Absolute) }\end{array}$ & $\begin{array}{l}\text { LEU/MNF } 2017 \\
\text { (Absolute) }\end{array}$ & $\begin{array}{l}\text { LEU/MNF } 2018 \\
\text { (Absolute) }\end{array}$ \\
\hline S1G2 & $106,793,840$ & $94,276,360$ & $104,978,800$ & $2,957,406$ & $2,544,410$ & $2,862,850$ \\
\hline S1G3 & $134,151,620$ & $124,700,430$ & $165,179,630$ & $7,693,141$ & $7,181,405$ & $9,637,075$ \\
\hline Pharmacy & $193,137,402$ & $210,177,201$ & $216,417,121$ & $5,093,515$ & $5,681,215$ & $5,846,784$ \\
\hline 01B2 & $83,858,450$ & $98,444,811$ & $103,622,407$ & $2,281,585$ & $3,043,918$ & $3,246,814$ \\
\hline 07A5 & $100,576,690$ & $104,101,960$ & $105,335,380$ & $2,088,516$ & $2,002,415$ & $2,000,027$ \\
\hline O1E1 & $5,926,522$ & $4,475,960$ & $4,168,654$ & 578,025 & 481,892 & 452,820 \\
\hline 07A2 & $2,775,740$ & $3,154,470$ & $3,290,680$ & 145,389 & 152,990 & 147,123 \\
\hline Discounter & $8,832,814$ & $8,353,946$ & $8,590,854$ & 257,229 & 197,507 & 193,400 \\
\hline 01B2 & $8,832,814$ & $8,353,946$ & $8,590,854$ & 257,229 & 197,507 & 193,400 \\
\hline Drugstore & $113,170,473$ & $114,023,434$ & $124,054,013$ & $1,999,975$ & $2,237,524$ & $2,572,119$ \\
\hline 01B2 & $86,313,303$ & $89,465,439$ & $100,583,488$ & $1,727,111$ & $1,780,528$ & $1,795,086$ \\
\hline O1E1 & $26,857,170$ & $19,024,460$ & $15,197,810$ & 272,864 & 184,562 & 174,842 \\
\hline 07A2 & 0 & $4,272,160$ & $4,959,840$ & 0 & 71,889 & 80,231 \\
\hline 07A5 & 0 & $1,261,375$ & $3,312,875$ & 0 & 200,545 & 521,960 \\
\hline S/Market & $38,898,835$ & $36,600,671$ & $37,537,948$ & 778,642 & 823,753 & 893,062 \\
\hline 01B2 & $30,506,765$ & $30,122,121$ & $32,530,143$ & 733,210 & 724,048 & 766,362 \\
\hline O1E1 & $8,392,070$ & $4,216,660$ & $3,629,200$ & 45,432 & 51,778 & 51,792 \\
\hline 07A2 & 0 & $2,176,640$ & $1,022,880$ & 0 & 34,308 & 18,346 \\
\hline 07A5 E & 0 & 85,250 & 355,725 & 0 & 13,619 & 56,562 \\
\hline Small SMKT & $4,446,616$ & $4,136,548$ & $4,429,041$ & 92,929 & 89,035 & 90,479 \\
\hline 01B2 & $3,781,336$ & $3,682,438$ & $3,562,601$ & 89,961 & 85,649 & 82,075 \\
\hline O1E1 & 665,280 & 372,290 & 680,470 & 2968 & 1762 & 3051 \\
\hline 07A2 & 0 & 81,120 & 172,320 & 0 & 1512 & 3166 \\
\hline 07A5 & 0 & 700 & 13,650 & 0 & 112 & 2187 \\
\hline Italy & $2,493,701,426$ & $2,460,288,900$ & $2,508,148,909$ & $221,605,769$ & $224,095,406$ & $230,723,070$ \\
\hline Hospital & $19,268,623$ & $20,624,634$ & $22,896,801$ & $7,307,742$ & $8,225,054$ & $7,737,864$ \\
\hline R1A1 & $2,637,698$ & $3,097,120$ & $6,309,450$ & 215,073 & 247,465 & 522,799 \\
\hline R1A7 & $6,402,915$ & $6,575,175$ & $6,376,050$ & 152,228 & 158,388 & 162,177 \\
\hline R6A0 & $6,641,693$ & $7,132,653$ & $6,905,066$ & $2,345,114$ & $2,494,632$ & $2,189,101$ \\
\hline V1A0 & $2,307,100$ & $2,676,768$ & $2,454,872$ & $4,557,923$ & $5,291,088$ & $4,839,904$ \\
\hline${ }^{*}$ Dymista & 12,628 & 18,840 & 90,240 & 1854 & 2762 & 13,228 \\
\hline S1G1 O & $1,120,848$ & $1,033,981$ & 791,298 & 31,163 & 27,931 & 20,146 \\
\hline $\mathrm{S} 1 \mathrm{G} 2$ & 8931 & 18,846 & 3785 & 448 & 750 & 179 \\
\hline S1G3 & 149,438 & 90,091 & 56,280 & 5793 & 4800 & 3558 \\
\hline Retail & $1,883,436,191$ & $1,844,094,607$ & $1,881,117,488$ & $176,870,734$ & $177,557,354$ & $184,265,292$ \\
\hline R1A1 & $496,427,232$ & $485,212,020$ & $499,795,900$ & $43,107,606$ & $42,304,966$ & $44,205,554$ \\
\hline R1A7 & $683,174,377$ & $678,502,447$ & $689,459,915$ & $40,119,423$ & $42,168,247$ & $44,414,520$ \\
\hline R6A0 & $372,064,000$ & $370,177,978$ & $377,874,748$ & $73,414,490$ & $72,901,327$ & $74,732,272$ \\
\hline V1A0 & 162,692 & 225,659 & 238,380 & 320,549 & 445,196 & 470,630 \\
\hline${ }^{*}$ Dymista & $30,759,112$ & $31,069,200$ & $36,225,840$ & $6,041,621$ & $6,102,510$ & $7,115,358$ \\
\hline S1G1 & $230,409,525$ & $214,051,423$ & $215,322,465$ & $10,608,676$ & $10,101,835$ & $10,384,357$ \\
\hline S1G2 & $35,852,210$ & $31,149,190$ & $31,040,290$ & $2,588,674$ & $2,362,103$ & $2,352,370$ \\
\hline S1G3 & $65,346,155$ & $64,775,890$ & $67,385,790$ & $6,711,316$ & $7,273,680$ & $7,705,589$ \\
\hline Off-Take & $420,390,759$ & $426,548,277$ & $441,534,997$ & $29,617,267$ & $30,277,427$ & $30,776,362$ \\
\hline 01B2 & $183,808,168$ & $183,945,839$ & $177,617,076$ & $8,938,640$ & $9,011,910$ & $8,847,760$ \\
\hline
\end{tabular}

(Continues) 
TABLE 5 (Continued)

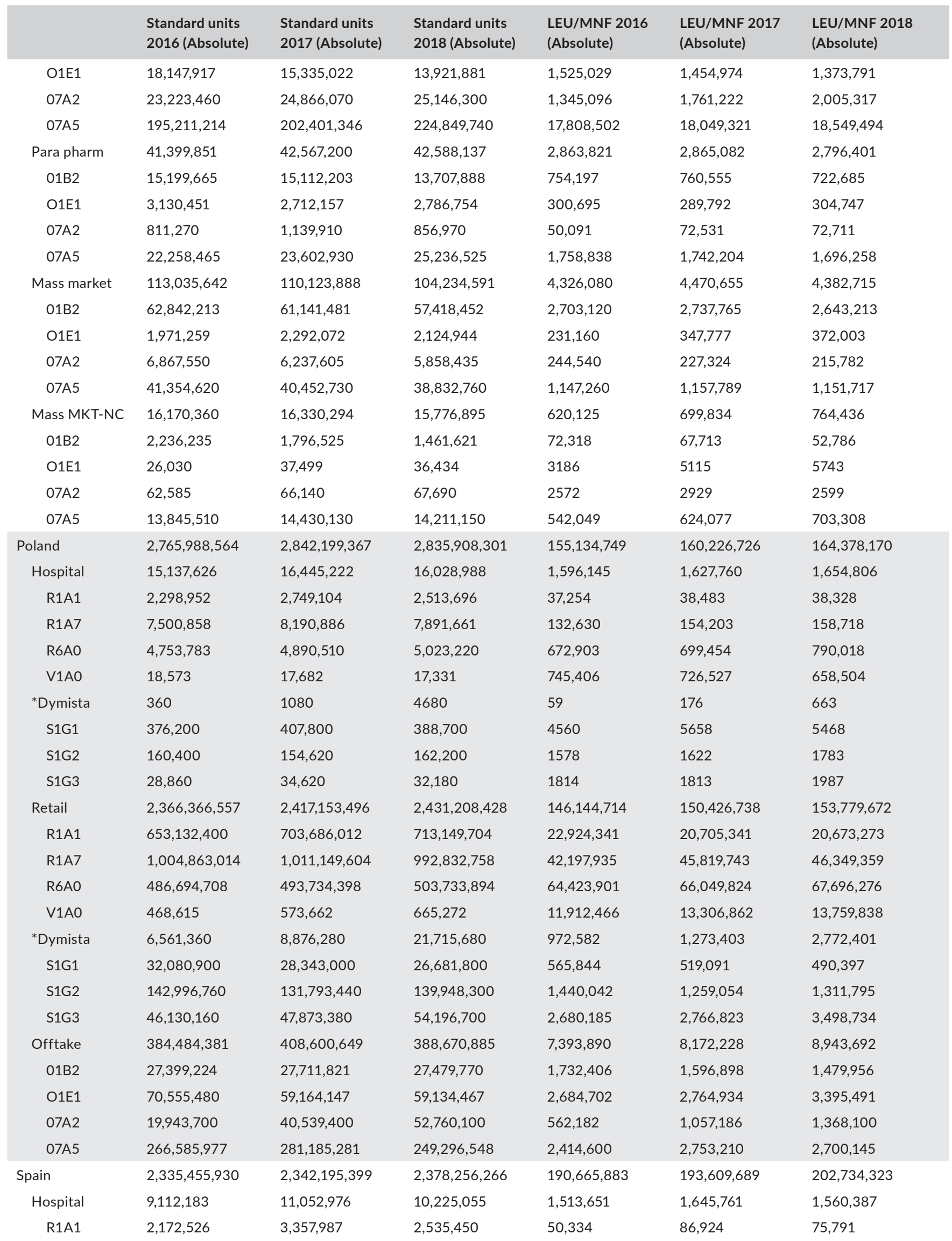


TABLE 5 (Continued)

\begin{tabular}{|c|c|c|c|c|c|c|}
\hline & $\begin{array}{l}\text { Standard units } \\
2016 \text { (Absolute) }\end{array}$ & $\begin{array}{l}\text { Standard units } \\
2017 \text { (Absolute) }\end{array}$ & $\begin{array}{l}\text { Standard units } \\
2018 \text { (Absolute) }\end{array}$ & $\begin{array}{l}\text { LEU/MNF } 2016 \\
\text { (Absolute) }\end{array}$ & $\begin{array}{l}\text { LEU/MNF } 2017 \\
\text { (Absolute) }\end{array}$ & $\begin{array}{l}\text { LEU/MNF } 2018 \\
\text { (Absolute) }\end{array}$ \\
\hline R1A7 & $2,005,927$ & $2,283,341$ & $2,158,777$ & 88,131 & 93,613 & 92,522 \\
\hline *Dymista & 0 & 0 & 0 & 0 & 0 & 0 \\
\hline S1G1 & 119,460 & 150,960 & 183,220 & 6728 & 8488 & 10,080 \\
\hline S1G3 & 777,141 & 859,961 & 894,912 & 58,871 & 63,533 & 64,926 \\
\hline Sell-out & $2,194,730,398$ & $2,195,372,883$ & $2,242,126,707$ & $180,353,377$ & $182,800,026$ & $191,487,364$ \\
\hline R1A1 & $855,946,916$ & $889,440,180$ & $919,688,976$ & $42,155,216$ & $45,579,352$ & $47,849,302$ \\
\hline R1A7 & $627,535,576$ & $601,079,486$ & $590,371,990$ & $28,513,887$ & $29,012,900$ & $29,795,483$ \\
\hline R6A0 & $457,352,438$ & $465,876,773$ & $487,974,761$ & $91,904,533$ & $91,040,256$ & $96,059,459$ \\
\hline $\mathrm{S} 1 \mathrm{G} 2$ & $33,539,100$ & $29,905,100$ & $29,050,300$ & 772,194 & 681,761 & 669,877 \\
\hline S1G3 & $108,627,980$ & $106,307,160$ & $106,879,880$ & $10,078,125$ & $9,861,257$ & $9,848,288$ \\
\hline Off-Take & $129,508,699$ & $131,988,535$ & $122,727,936$ & $8,702,319$ & $8,969,019$ & $9,517,896$ \\
\hline 01B2 & $46,051,527$ & $42,168,335$ & $38,740,393$ & $2,714,808$ & $2,595,648$ & $2,513,212$ \\
\hline O1E1 & $4,814,504$ & $4,447,039$ & $5,056,991$ & $1,025,215$ & 760,457 & 834,638 \\
\hline 07A2 & 184,714 & 434,790 & $2,210,500$ & 57,610 & 131,428 & 218,062 \\
\hline 07A5 & $78,457,954$ & $84,938,371$ & $76,720,052$ & $4,904,686$ & $5,481,486$ & $5,951,984$ \\
\hline Parapharm & $2,104,650$ & $3,781,005$ & $3,176,568$ & 96,536 & 194,883 & 168,676 \\
\hline
\end{tabular}

(conditional recommendation, very low-quality evidence). A report by Statistica (https://www.statista.com/statistics/417727/cough -and-cold-self-medication-market-sales-in-europe/) showed the same ranking order for cold and cough drugs as the IQVIA data for nasal decongestants. Germany ranked first (1,557 million € for 2017), followed by Italy (718), Poland (609), Spain (552) and France (490). In Germany, in 2018, the months with the highest pollen counts were those with the lowest use of nasal decongestants.

\section{2 | Interpretation}

Although many papers dealt with AR costs, we were not able to find any that analyzed the units sold. Moreover, costs are difficult to compare between papers as OTC and prescribed drugs vary between countries, and direct AR costs reduced considerably when OTC medications became available. In the present paper, we found large differences between EU countries and particularly between France (low nasal decongestants, high INCS consumption) and Germany (the opposite).

In a Swedish study, it was found that $71.6 \%$ of patients with AR were using OAH, 44\% INCS and $41 \%$ nasal decongestants. ${ }^{21}$
In France, most medications are reimbursed if prescribed. A long wait to consult French medical specialists encourages the quick purchase of OTC drugs, during pollen seasons, for example. French pharmacists are often well trained for offering OTC drugs: easy-touse, inexpensive oral OAH, nasal sprays and eye drops. ENT physicians and allergists traditionally prescribe these molecules and train general practitioners to also do so. These molecules were prescribed very early by pediatricians, also to children of atopic families who present nasal signs. These children are used to these methods from the age of 3 .

In Germany, the situation is more complex than in other countries. The general reimbursement strategy is outlined in Table 4. $8.7 \%$ of the population are privately insured; this is only possible for people who are self-employed or for employees who earn an above-average salary. For privately insured patients, all allergic rhinitis medications are usually reimbursed but this depends very much on the individual contracts. Some privately insured patients, for instance, have a contract where they are only reimbursed for medications and other healthcare costs above a chosen limit, for example $1,000 €$ per year. This is a contract which young people very often choose, with the monthly costs being lower and the speculation of not having to use this fixed rate in the year. These patients often tend 
FIGURE 1 Comparison between countries for 2018 of the number of standard units sold (SU) and costs (LEU/ MNF) Incs include dymista

\section{SU absolute values 2018}

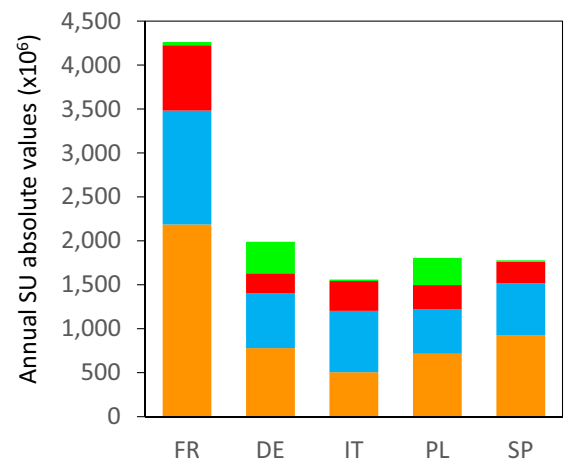

Costs - MNF/LEU (€) 2018

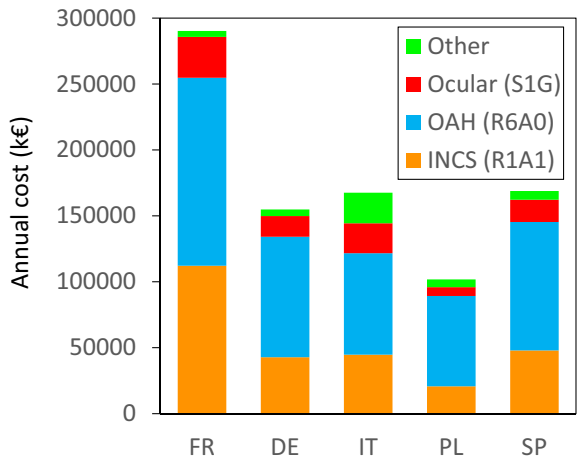

TABLE 6 Rhinoconjunctivitis medication consumption in Europe per inhabitant (results in SU per year, 2018)

\begin{tabular}{|lllcl|}
\hline & $\begin{array}{l}\text { Population } \\
\text { thousands) }\end{array}$ & $\begin{array}{l}\text { All without nasal } \\
\text { decongestants }\end{array}$ & $\begin{array}{l}\text { Nasal } \\
\text { decongestants }\end{array}$ & INCS \\
\hline France & 66,352 & 64.2 & 9.2 & 33 \\
\hline Germany & 81,175 & 24.5 & 85.1 & 7.6 \\
\hline Italy & 60,795 & 25.7 & 15.6 & 8.3 \\
\hline Poland & 38,005 & 47.5 & 27.0 & 18.8 \\
\hline Spain & 46,440 & 36.5 & 13.7 & 20.0 \\
\hline
\end{tabular}

not to buy medications recommended by the physician. The rest of the population is under the statutory health insurance (Gesetzliche Krankenversicherung) but can choose between policies of different companies. Also, the official healthcare insurance companies have different reimbursement strategies, and details vary. The general reimbursement strategy is outlined in Table 4 but another variable comes into play. Physicians treating patients under the statutory health insurance scheme in Germany have a fixed budget for medication costs and can be made liable if they do not adhere to the very strict economic prescription pathways. Although $\mathrm{OAH}$ can be reimbursed for severe allergic rhinitis, even if over-the-counter products are available, physicians often choose not to prescribe these medications on a panel prescription allowing reimbursement. They choose rather to give a private prescription to the patient which means that he/she has to cover the full costs. Last but not least, another limiting factor in Germany is the fact that all patients above 12 years of age also have to pay a cost share fee for every drug at the pharmacy $(10 \%$ of the price of the product), with a minimum of $5 €$ and maximum of $10 €$.

In Italy, most medications for rhinoconjunctivitis are provided through medical prescription. $\mathrm{OAH}$ are reimbursed by the NHS (National Healthcare System), whereas INCS (including INCS + INAH) are not, except in the region of Tuscany.

In Poland, the situation is similar to France. The medications for Allergic Rhinoconjunctivitis are reimbursed if prescribed by the physician. Everyone is covered by the National Health Fund (NHF), but the private sector is also very active. Patients can visit specialists working under the NHF for free, but they have to wait for a few months to consult. Otherwise, they can choose to visit a private doctor and pay out of pocket for the service without having to wait. Physicians in private and public sectors can prescribe reimbursed medications. Many medications which are reimbursed if prescribed also have an OTC version, including INCS and OAH. Similar to France, these molecules were prescribed very early by pediatricians, also to children of atopic families who present nasal symptoms. These children are used to these methods from the age of 2. In Poland, nasal washing with isotonic saline is also very common.

In Spain, most medications for rhinoconjunctivitis are provided through medical prescription. Nevertheless, there are a few formulations which may be acquired as OTC, including some $\mathrm{OAH}$, such as cetirizine, and INCS, such as fluticasone propionate. A recent study has calculated the direct and indirect costs of AR in patients attending specialized clinics in Spain. ${ }^{22}$ Data showed that the mean drug treatment per year was significantly higher in persistent $A R$ (77.88 $\pm 134.22 €)$ compared to intermittent AR (45.62 $\pm 78.93 €)$. On the other hand, no significant differences were found when comparing mild, moderate and severe AR $(41.77 \pm 86.02 €, 70.36 \pm 127.07 €$ and $72.16 \pm 114.60 €$, respectively). Direct costs accounted for $24 \%$ of total costs, and drug therapy was only $10 \%-13 \%$ of the direct costs.

Cultural and reimbursement differences between countries may explain trends in treatment.

Many studies reported that $\mathrm{OAH}$ are more often used than INCS ${ }^{23-25}$ and this accords with the results of the present study. However, this is the first multi-national study to compare medication delivery.

The large differences between countries in INCS use are surprising since the guidelines of ARIA, ${ }^{26}$ the British Society of Allergy and Clinical Immunology ${ }^{19}$ and the US Practice parameters ${ }^{27}$ all recommend INCS as the first-line treatment for moderate to severe AR and 
it is likely that AR severity is similar between countries. However, the reimbursement strategies of some countries may impair the implementation of guidelines. Moreover, although most AR patients consulting a physician have moderate to severe rhinitis, the low level of ICNS prescribed is surprising. These data may at least partly explain the poor satisfaction of AR patients.

There are also very large differences between countries in intranasal decongestants. Although the indications cannot be assessed using the IQVIA database, it is likely that many patients in Germany use intranasal decongestants for AR. This does not accord with guidelines. In ARIA, 'in adults with AR and severe nasal obstruction, we suggest a very short course (no longer than 5 days, and preferably shorter) of intranasal decongestants while co-administering other drugs (conditional recommendation, very low-quality evidence)'. ${ }^{20}$

\section{5 | CONCLUSIONS}

With the limitations discussed, this study is of great interest for assessing the heterogeneity of pharmacotherapy in some European countries and can be used as a baseline for future studies to show treatment trends.

\section{CONFLICT OF INTEREST}

CB reports personal fees from Meda. JB reports personal fees from Chiesi, Cipla, Hikma, Menarini, Mundipharma, Mylan, Novartis, Purina, Sanofi-Aventis, Takeda, Teva, Uriach, other from KYomed-Innov, outside the submitted work. VC reports personal fees from ALK, Allergopharma, Allergy Therapeutics, Diater LETI, Thermofisher, Stallergenes, outside the submitted work. PD reports personal fees and non-financial support from Astra Zeneca, Chiesi, personal fees from Mylan, personal fees from Sanofi, GlaxoSmithKline, Menarini, outside the submitted work. LK reports grants and personal fees from Allergopharma, LETI Pharma, MEDA/Mylan, Sanofi, personal fees from HAL Allergie, Allergy Therapeut, grants from ALK Abelló, Stallergenes, Quintiles, ASIT biotech, Lofarma, AstraZeneca, GSK, Inmunotk outside the submitted work; and Membership: AeDA, DGHN, Deutsche Akademie für Allergologie und klinische Immunologie, HNO-BV GPA, EAACI. OP reports grants and personal fees from ALK-Abelló, Allergopharma, Anergis S.A.,, Stallergenes Greer, HAL Allergy Holding B.V./HAL Allergie $\mathrm{GmbH}$, Bencard Allergie GmbH/Allergy Therapeutics, Lofarma, ASIT Biotech Tools S.A., Laboratorios LETI/LETI Pharma, grants from Biomay, Circassia, Glaxo Smith Kline, personal fees from MEDA Pharma/MYLAN, Mobile Chamber Experts (a GA2LEN Partner), Indoor Biotechnologies, Astellas Pharma Global, EUFOREA, ROXALL, NOVARTIS, SANOFI AVENTIS, Med Update Europe $\mathrm{GmbH}$, streamedup! $\mathrm{GmbH}$, outside the submitted work. BS reports grants from AstraZeneca, personal fees from Mylan, Polpharma, outside the submitted work. GS reports personal fees from ALK- Abello, Mylan, GSK, Bayer outside the submitted work. EVG reports personal fees from PELyon, outside the submitted work. TZ reports: Organizational affiliations:Commitee member: WHO-Initiative 'Allergic Rhinitis and Its Impact on Asthma' (ARIA), Member of the Board: German Society for Allergy and Clinical Immunology (DGAKI); Head: European Centre for Allergy Research Foundation (ECARF); President: Global Allergy and Asthma European Network (GA ${ }^{2}$ LEN). Member: Committee on Allergy Diagnosis and Molecular Allergology, World Allergy Organization (WAO).

\section{AUTHOR CONTRIBUTIONS}

Jean Bousquet designed and interpreted the study data and wrote the paper. Detlef Schröder-Bernhardi co-designed the study and participated in the analysis interpretation. Claus Bachert, G. Walter Canonica, Victoria Cardona, Elisio M Costa, Wienczyslawa Czarlewski, Philippe Devillier, Joao A. Fonseca, Ludger Klimek, Piotr Kuna, Olga Lourenco, Joaquim Mullol, Oliver Pfaar, Nhân PhamThi, Boleslaw Samolinski, Glenis Scadding, Sophie Scheire, Eric Van Ganse, Torsten Zuberbier interpreted the data and reviewed the paper. They all gave their agreement for the publication. Julia Saueressig, Ann-Kathrin Stroh analyzed the data.

\section{DATA AVAILABILITY STATEMENT}

The data is the property of IQVIA.

\section{ORCID}

Jean Bousquet (D) https://orcid.org/0000-0002-4061-4766

Victoria Cardona (D) https://orcid.org/0000-0003-2197-9767

Philippe Devillier (D) https://orcid.org/0000-0001-6054-1886

Oliver Pfaar (D) https://orcid.org/0000-0003-4374-9639

Eric Van Ganse (D) https://orcid.org/0000-0002-7463-9187

\section{REFERENCES}

1. Bousquet J, Anto JM, Bachert C, et al. Allergic rhinitis. Nat Rev Dis Primers. 2020;6(1):95.

2. Bedard A, Basagana X, Anto JM, et al. Mobile technology offers novel insights into the control and treatment of allergic rhinitis: the MASK study. J Allergy Clin Immunol. 2019;144(1):135-143.e6.

3. Bedard A, Basagana X, Anto JM, et al. Treatment of allergic rhinitis during and outside the pollen season using mobile technology. A MASK study. Clin Transl Allergy. 2020;10(1):62.

4. Bousquet J, Anto JM, Annesi-Maesano I, et al. POLLAR: Impact of air POLLution on Asthma and Rhinitis; a European Institute of Innovation and Technology Health (EIT Health) project. Clin Transl Allergy. 2018;8:36.

5. Bousquet J, Arnavielhe S, Bedbrook A, et al. MASK 2017: ARIA digitally-enabled, integrated, person-centred care for rhinitis and asthma multimorbidity using real-world-evidence. Clin Transl Allergy. 2018;8:45.

6. Bousquet JJ, Schunemann HJ, Togias A, et al. Next-generation ARIA care pathways for rhinitis and asthma: a model for multimorbid chronic diseases. Clin Transl Allergy. 2019;9:44.

7. Bousquet J, Bedbrook A, Czarlewski W, et al. Guidance to 2018 good practice: ARIA digitally-enabled, integrated, person-centred care for rhinitis and asthma. Clin Transl Allergy. 2019;9:16.

8. Valiulis A, Bousquet J, Veryga A, et al. Vilnius Declaration on chronic respiratory diseases: multisectoral care pathways embedding guided self-management, $\mathrm{mHealth}$ and air pollution in chronic respiratory diseases. Clin Transl Allergy. 2019;9:7. 
9. Van Boeckel TP, Gandra S, Ashok A, et al. Global antibiotic consumption 2000 to 2010: an analysis of national pharmaceutical sales data. Lancet Infect Dis. 2014;14(8):742-750.

10. Collignon P, Beggs JJ, Walsh TR, Gandra S, Laxminarayan R. Anthropological and socioeconomic factors contributing to global antimicrobial resistance: a univariate and multivariable analysis. Lancet Planet Health. 2018;2(9):e398-e405.

11. Kenyon C, Manoharan-Basil SS. Cultural drivers of antibiotic consumption in high-income countries: a global ecological analysis. Microb Drug Resist. 2020;26(9):1063-1070.

12. Tu CM. Use of proprietary names by prescribers when prescribing Over-the-Counter (OTC) drug products. Ther Innov Regul Sci. 2019;53(1):132-137.

13. Wastesson JW, Martikainen JE, Zoega H, Schmidt M, Karlstad O, Pottegard A. Trends in use of paracetamol in the Nordic countries. Basic Clin Pharmacol Toxicol. 2018;123(3):301-307.

14. Wertheimer Al. The defined daily dose system (DDD) for drug utilization review. Hosp Pharm. 1986;21(3):233-234, 9-41, 58.

15. Tollier C, Fusier I, Husson MC. ATC and EphMRA classifications: evolution from 1996 to 2003 and comparative analysis. Therapie. 2005;60(1):47-56

16. EPHMRA. Anatomical classification. Guidelines 2016. https:// webarchiveorg/web/20160423224519/http:/wwwephmraorg/ user_uploads/atcguidelines2016finalpdf; 2016.

17. Comparison of the WHO ATC classification and EphMRA/PBIRG anatomical classification. Version 3. https://webarchiveorg/ web/20150806235351/http:/wwwephmraorg/user_uploads/ who-atc\%202013\%20finalpdf. 2013.

18. Menditto E, Costa E, Midao L, et al. Adherence to treatment in allergic rhinitis using mobile technology. The MASK Study. Clin Exp Allergy. 2019;49(4):442-460.

19. Scadding GK, Kariyawasam HH, Scadding G, et al. BSACl guideline for the diagnosis and management of allergic and non-allergic rhinitis (Revised Edition 2017; First edition 2007). Clin Exp Allergy. 2017;47(7):856-889.

20. Brozek JL, Bousquet J, Baena-Cagnani CE, et al. Allergic rhinitis and its impact on Asthma (ARIA) guidelines: 2010 revision. J Allergy Clin Immunol. 2010;126(3):466-476.
21. Cardell LO, Olsson P, Andersson M, et al. TOTALL: high cost of allergic rhinitis-a national Swedish population-based questionnaire study. NPJ Prim Care Respir Med. 2016;26:15082.

22. Colas C, Brosa M, Anton E, et al. Estimate of the total costs of allergic rhinitis in specialized care based on real-world data: the FERIN Study. Allergy. 2017;72(6):959-966.

23. Hellings PW, Dobbels F, Denhaerynck K, Piessens M, Ceuppens JL, De Geest S. Explorative study on patient's perceived knowledge level, expectations, preferences and fear of side effects for treatment for allergic rhinitis. Clin Transl Allergy. 2012;2(1):9.

24. Smith P, Price D, Harvey R, et al. Medication-related costs of rhinitis in Australia: a NostraData cross-sectional study of pharmacy purchases. J Asthma Allergy. 2017;10:153-161.

25. Bousquet PJ, Devillier P, Tadmouri A, Mesbah K, Demoly P, Bousquet J. Clinical relevance of cluster analysis in phenotyping allergic rhinitis in a real-life study. Int Arch Allergy Immunol. 2015;166(3):231-240.

26. Brozek JL, Bousquet J, Agache I, et al. Allergic Rhinitis and its Impact on Asthma (ARIA) guidelines-2016 revision. J Allergy Clin Immunol. 2017;140(4):950-958.

27. Wallace DV, Dykewicz MS. Comparing the evidence in allergic rhinitis guidelines. Curr Opin Allergy Clin Immunol. 2017;17:286-294.

\section{SUPPORTING INFORMATION}

Additional supporting information may be found online in the Supporting Information section.

How to cite this article: Bousquet J, Schröder-Bernhardi D, Bachert C, et al. Heterogeneity of the pharmacologic treatment of allergic rhinitis in Europe based on MIDAS and OTCims platforms. Clin Exp Allergy. 2021;51:1033-1045. https://doi.org/10.1111/cea.13884 